\title{
Kesultanan Banjar: Peranan dalam persebaran Islam di Kalimantan (abad XVI M - XIX M)
}

\author{
Alfrida Dyah Miranti, Lutfiah Ayundasari* \\ Universitas Negeri Malang, Jl. Semarang No. 5 Malang, Jawa Timur, Indonesia \\ *Penulis korespondensi, Surel: lutfiah.ayundasari.fis@um.ac.id
}

Paper received: 03-02-2021; revised: 15-02-2021; accepted: 28-02-2021

\begin{abstract}
Several theories and hypotheses suggest that Islam entered the archipelago around the VII century AD or XIII AD. Thus, the entry of Islam led to the emergence of Islamic kingdoms or often known as the Sultanate. In Kalimantan, there is an Islamic kingdom, namely the Banjar Sultanate. The Demak Sultanate influenced the process of developing Islam in the Banjar Sultanate. After getting the influence of Islam, the Banjar Sultanate government made efforts to Islamize several areas where the people were not yet Muslim with the help of local scholars. Since the arrival of the scholars in Kalimantan, the process of spreading Islam began to develop rapidly. On this basis, the purpose of the preparation of this article is to determine the process of Islamization in the Banjar Sultanate from the XVI M to XIX M centuries. The methods used are historical and qualitative methods, namely in the form of Library Research. This article contains about the condition of Banjar before the entry of Islam, the process of spreading Islam, and the ulama who played a role in the process of spreading Islam in the Banjar Sultanate.
\end{abstract}

Keywords: Banjar Sultanate; Islamization; ulama Sultanate Banjar.

\begin{abstract}
Abstrak
Beberapa teori dan hipotesa yang menganggap bahwa Islam memasuki wilayah Nusantara sekitar abad ke VII M atau XIII M. Sehingga, masuknya Islam menyebabkan munculnya kerajaan-kerajaan bercorak Islam atau yang sering dikenal dengan Kesultanan. Di Kalimantan terdapat kerajaan Islam yaitu Kesultanan Banjar. Proses perkembangan agama Islam di Kesultanan Banjar dipengaruhi oleh Kesultanan Demak. Setelah mendapatkan pengaruh Islam maka pemerintah Kesultanan Banjar melakukan upaya Islamisasi dibeberapa wilayah yang masyarakatnya belum beragama Islam dengan dibantu oleh ulama setempat. Sejak kedatangan para ulama di Kalimantan, proses penyebaran agama Islam mulai berkembang pesat. Atas dasar tersebut maka tujuan dari penyusunan artikel ini adalah untuk mengetahui proses Islamisasi pada Kesultanan Banjar dari abad XVI M hingga XIX M. Metode yang digunakan adalah metode history dan kualitatif yaitu berupa Library Research. Artikel ini berisikan tentang kondisi Banjar sebelum masuknya Islam, proses penyebaran agama Islam, dan ulama yang berperan dalam proses penyebaran agama Islam di Kesultanan Banjar.
\end{abstract}

Kata kunci: Kesultanan Banjar; Islamisasi; ulama Kesultanan Banjar.

\section{Pendahuluan}

Pengaruh penyebaran agama Hindu-Buddha di Nusantara mulai pudar ketika beberapa kerajaan yang berlatar belakang agama Hindu-Buddha mulai diambang keruntuhan dan diwaktu yang sama, agama Islam mulai masuk serta menyebarkan pengaruhnya di beberapa wilayah Nusantara. Terdapat beberapa hipotesa mengenai tahun masuknya agama Islam di Nusantara, ada yang mengatakan bahwa agama Islam masuk di Nusantara pada abad ke VII M dan ada pula yang menyatakan pada abad ke XIII M. Agama Islam dibawa oleh para pengembara dari luar Nusantara dengan berbagai metode dan pendekatan yang dapat diterima secara terbuka oleh masyarakat setempat. Pendekatan yang dilakukan oleh para pengembara tersebut antara lain melalui jalur perdagangan, pernikahan, proses struktur 
sosial, jalur pendidikan, seni dan budaya, serta dengan ajaran tasawuf. Setelah agama Islam mulai berkembang maka mulai muncul beberapa kerajaan di Nusantara berbasis agama Islam yang dikenal dengan sebutan kesultanan dengan rajanya bergelar Sultan. Dengan didirikannya kesultanan Islam dibeberapa wilayah maka agama Islam dapat menyebar sangat luas bahkan dapat mempengaruhi setiap elemen kehidupan di masyarakat.

Kesultanan Demak hingga saat ini diyakini sebagai kesultanan pertama yang berdiri di Pulau Jawa dan dikenal dengan hegemoninya serta ulama-ulama (Wali Songo) yang memiliki peranan penting dalam Islamisasi di pulau Jawa melalui pendekatan yang dapat diterima oleh masyarakat setempat. Sedangkan di Kalimantan berdiri kesultanan Islam yang dikenal dengan nama Kesultanan Banjar. Dalam perkembangannya, Islam di Kalimantan jauh lebih terbelakang apabila dibandingkan dengan perkembangan agam Islam di beberapa wilayah, misalnya Aceh. Perkembangan Islam di Kalimantan banyak mendapat pengaruh dari Kesultanan Demak. Setelah pasukan Kesultanan Demak datang ke Banjarmasin untuk membantu Pangeran Samudra untuk melawan kalangan elit dari Kerajaan Daha. Kemudian pasukan dari Kesultanan Banjar memperoleh kemenangan atas bantuan dari Kerajaan Demak. Atas kemenangannya inilah Kesultanan Banjar serta merta memeluk agama Islam berdasar kesepakatan dengan Kerajaan Demak. Di perkirakan Islam masuk ke Kalimantan sekitar abad XVI M. Namun perkembangan Islam pada masa awal ini hanya dipeluk oleh kalangan etnik Melayu, sedangkan dari kalangan etnik suku Dayak sendiri masih terbatas. Proses Islamisasi di Kalimantan juga tidak terlepas oleh peran-peran para ulama yang terus berdakwah di Kalimantan guna membantu proses islamisasi yang menyeluruh. Atas pemaparan tersebut kami menemukan tiga permasalahan guna lebih mengkaji Islamisasi di Kesultanan Banjar abad XVI M hingga XIX M antara lain bagaimana kondisi Kesultanan Banjar pra-Islam, proses Islamisasi di Kalimantan masa Kesultanan Banjar, dan ulama-ulama yang berperan penting dalam proses Islamisasi di Kesultanan Banjar pada abad ke XVI M hingga XIX M.

\section{Metode}

Pada artikel ini peneliti menggunakan jenis penelitian yang berupa Library Research sebagai salah satu upaya untuk mengumpulkan data dengan pengambilan kesimpulan dari buku-buku yang ada di perpustakaan maupun dari sumber online/jurnal online. Tujuan dari penyusunan artikel ini adalah untuk mendeskripsikan serta menganalisis Islamisasi masa Kesultanan Banjar pada abad ke XVI M hingga XIX M. Adapun pendekatan yang digunakan dalam penyusunan artikel ini adalah pendekatan kualitatif yang merupakan usaha pendekatan guna menemukan suatu jawaban atas problematika yang sedang ditelaah atau dikaji dan penyusunannya berupa deskriptif-naratif.

\section{Hasil dan Pembahasan}

\subsection{Kondisi Kesultanan Banjar Pra-Islam}

Banjarmasin merupakan wilayah yang menjadi bagian dari Kalimantan Selatan. Banjarmasin berasal dari kata Banddar Massih yang merupakan nama ibukota pertama di Kesultanan Banjarmasin dibawah pimpinan Kesultanan Suriansyah tahun 1526-1550 (Saleh, 1983). Kesultanan Banjar berada di tepi Sungai Kuin (Cerucuk) yang bermuara ke sungai besar, yakni Sungai Barito dan Sungai Martapura. Berada pada posisi $3^{\circ} 15^{\prime}$ Lintang Selatan, $145^{\circ} 35^{\prime}$ Bujur Timur dengan luas wilayah 9.291,975 km kubik. Wilayah Banjarmasin dikelilingi dengan laut-laut di bagian Selatan dan wilayah pegunungan di bagian Timur, ke Utara daerah sekitar 
Sungai Negara dan disebelah barat meliputi aliran sepanjang Sungai Barito. Sebelum Islamisasi muncul di Kalimantan Selatan, Kerajaan Banjar yang merupakan kelanjutan dari Kerajaan Daha bercorak agama Hindu.

Kesultanan Banjar merupakan penerus dari kerajaan Hindu di Kalimantan Selatan yaitu Kerajaan Daha dengan wilayah inti meliputi 5 distrik besar di Kalimantan Selatan yaitu Kuripan (Amuntai), Gagelang (Alabio), Daha (Nagara-Margasari), Pandan Arum (Tanjung), dan Pudak Sategal (Kalua). Kerajaan Nagara Dipa masa pemerintahan Putri Jungjung Built dan Patihnya Lembu Amangkurat, pernah melakukan hubungan baik dengan Kerajaan Majapahit (Hardiati, 2008). Pengaruh Majapahit sudah sampai di daerah sungai Nagara sudah tercatat dalam Nagarakertagama. Pada akhir abad ke-15 Kalimantan Selatan dibawah pimpinan Kerajaan Daha yang dipimpin oleh Pangeran Sukarama. Pangeran Sukarama memiliki empat orang anak dari empat istri yaitu Pangeran Mangkubumi, Pangeran Tumanggung, Pangeran Bagalung, Pangeran Jayadewa, dan si bungsu perempuan bernama Putri Galuh.

Kemunculan Kerajaan Banjar berawal dari konflik yang dimulai ketika terjadi pertentangan dalam keluarga istana. Konflik terjadi antara Pangeran Samudera dengan pamannya Pangeran Tumenggung, yang mana Pangeran Samudera adalah pewaris sah Kerajaan Daha (Zuhri, 1979:386). Hikayat banjar menyebutkan bahwa pada saat Kerajaan Daha dipimpin oleh Raja Sukarama, pada akhir hayatnya berwasiat agar yang menggantikan posisinya adalah cucunya yaitu Raden Samudera. Mendapatkan berita tersebut, anak-anak kandungnya menyatakan tidak setuju dengan keputusan ayahnya. Terutama Pangeran Tumenggung yang memiliki ambisi besar untuk dapat menguasai Kerajaan Daha. Setelah Raja Sukarama meninggal, jabatan raja digantikan oleh anak tertuanya yakni Pangeran Mangkubumi, pengangkatan ini dilakukan karena pada saat itu Pangeran Sukarama masih belum cukup umur, ia masih berusia 7 tahun. Atas alasan itulah setelah Raja Sukarama meninggal yang diangkat menjadi raja adalah anak tertuanya bukan cucunya yang sesuai dengan apa yang dituliskan dalam warisannya.

Pangeran Mangkubumi tidak lama berkuasa, karena ia dibunuh oleh salah satu pengawai istana yang pada saat itu dipengaruhi Pangeran Tumenggung karena ambisinya. Setelah sepeninggal Mangkubumi, akhirnya Pangeran Tumenggung yang menggantikan posisi raja dalam Kerajaan Daha. Masa kepemimpinan Pangeran Tumenggung, musuh utama nya adalah Pangeran Samudera. Pangeran Samudera memilih untuk meninggalkan lingkungan istana, serta menyamar dan menjadi nelayan yang ada di Pelabuhan Banjar, akan tetapi keberadaannya diketahui oleh Patih Masih seorang mentri yang cakap dalam menjalankan pemerintahan. Patih ini banyak bergaul dengan para ulama-ulama agama Islam datang dari Tuban dan Gresik, serta banyak mendengarkan cerita tentang Wali Songo yang dapat mengembangkan Kerajaan Demak karena itulah akhirnya Patih Masih memeluk agama islam. Pangeran Samudera dapat menghimpun banyak kekuatan untuk melawan Pangeran Tumenggung berkat bantuan dari Patih Masih (Zuhri, 1979).

Peperangan antara Pangeran Tumenggung dan Pangeran Samudera terus berlangsung, sampai akhirnya Pangeran Samudera meminta bantuan kepada Kerajaan Demak dan permintaannya disetujui oleh sultan dari Kerajaan Demak akan tetapi dengan syarat bahwa Pangeran Samudera harus memeluk agama Islam. Sultan Demak kemudian mengirimkan bantuan seribu orang tentara beserta dan seorang penghulu bernama Khatib Dayan untuk mengislamkan Pangeran Samudera beserta seluruh masyarakat Banjar (Yatim, 1997:386). 
Berkat bantuan dari Sultan Demak Pangeran Samudera berhasil memenangkan perang keluarga tersebut, sesuai dengan janjinya, ia beserta seluruh kerabat kraton dan rakyat Banjar untuk menyatakan diri masuk Islam. Setelah masuk Islam pada tahun 1526 M, Kerajaan Daha berubah menjadi Kerajaan Islam Banjar dan Pangeran Samudera pun diberi gelar Sultan Suryanullah atau Sultan Suriansyah, yang dinobatkan sebagai raja pertama dalam Kerajaan Islam Banjar.

Kondisi kehidupan sosial masyarakat sebelum kedatangan Islam beraneka ragam. Masyarakat Banjarmasin yang hidup disepanjang aliran sungai untuk dapat memenuhi kebutuhan hidupnya, mata pencaharian yang dilakukan adalah dengan mengembangkan sektor pertanian dengan cara bertani, berkebun, mengelola hasil laut dan juga dalam bidang pertambangan dan melakukan perdagangan. Wilayah yang dijadikan persawahan adalah wilayah di sekitar Sungai Barito. Hasil pertanian dan perkebunan yang dihasilkan oleh petani pada saat itu sudah beragam yang meliputi lada, sayur mayur kopi-kopian dan lain-lain. Selain hasil pertanian, masyarakat juga memanfaatkan hasil hutan di wilayahnya yaitu meliputi kayu rotan, damar, kayu jati dan lain-lain. Disamping itu masyarakat juga banyak melakukan aktivitas perdagangan karena wilayah yang strategis untuk melakukan perdagangan berbagai jenis barang. Sedangkan kehidupan religi masyarakat Banjarmasin sebelum kedatangan agama Islam, masyarakatnya menganut agama Hindu yang dipengaruhi oleh Kerajaan Majapahit (Daha). Akan tetapi disamping agama Hindu yang berkembang, pada saat itu pula juga masih berkembang agama nenek moyang yang ada di Nusantara. Agama tersebut adalah animisme dan dinamisme.

\subsubsection{Proses Islamisasi Masa Kesultanan Banjar Pada Abad XVI M Hingga XIX M}

Sejak runtuhnya kekuasaan dari kerajaan-kerajaan yang bercorak Hindu-Budha akhir abad ke-15 kehidupan pada masyarakat Nusantara mengalami banyak perubahan dalam segala aspek, terlebih perkembangan Islam di Kalimantan Selatan lebih pesat dibandingkan dengan perkembangan Islam di Aceh. Islam baru berkembang secara massive pada saat Kesultanan Demak dari Jawa datang ke Banjarmasin untuk membantu perjuangan Pangeran Samudra dalam menghadapi kaum elit istana Kerajaan Daha. Ketika kemenangan berpihak pada Pangeran Samudra, kemudian ia serta merta memeluk agama Islam berdasarkan atas kesepakatan dengan Sultan Demak sekitar tahun 936 H/ 1526 M (Kartodirdjo, 1987:24-25). Dengan demikian secara sepintas proses Islamisasi pada masyarakat Banjar, memiliki hubungan yang sangat kuat dengan Kesultanan Demak karena setelah runtuhnya kekuasaan dari Kerajaan Majapahit yang bercorak Hindu telah memiliki pengaruh besar dalam proses pengislaman sultan pertamanya yaitu Pangeran Samudra sehingga Pemahaman penyebaran penyebaran islam di Banjarmasin yang meliputi daerah Kalimantan bagian Selatan, Tengan, dan Timur diartikan sebagai bentuk ekspansi dan kekerasan. Apalagi didukung dengan buktibukti peninggalan dari kerajaan-kerajaan yang bercorak Hindu-Budha seperti Candi Agung dan Candi Laras hanya meninggalkan sisa-sisa reruntuhan bangunan yang hancur seakan-akan disebabkan oleh penyerbuan pasukan Demak. Padahal, dalam sebuah hikayat yaitu Hikayat Banjar disebutkan bahwa Kesultanan Demak sendiri mengutus seorang Khatib yang bernama Khatib Dayyan ke Banjarmasin. Gelar atau nama Khatib Dayyan lebih mencerminkan nama dari seorang penyemapai Khotbah penyiar agama daripada nama dari seorang panglima perang.

Proses Islamisasi yang terjadi di Kesultanan Banjar melalui saluran perdagangan, saluran pernikahan, dan saluran kesenian. Kesultanan Banjar yang mengayomi komunitas 
pedagang sekaligus sebagai kesultanan yang mengendalikan perdagangan lada, khususnya pada abad ke-17 $\mathrm{M}$ dan abad ke-18 $\mathrm{M}$ berhasil membentuk jaringan perdagangan dari pedalaman ke muara sungai, dari muara sungai hingga ke muara sungai Barito yang langsung bersambung dengan Laut Jawa (Lapian, 2008:49), sehingga yang melakukan perdagangan di daerah Banjar bukan hanya dari masyrakat Jawa maupun sekitar Pulau Kalimantan namun juga pedagang yang berasal dari luar Nusantara seperti China dan Arab. Pedagang-pedagang Arab mulai abad ke-16 M sejak Kesultanan Banjar dipimpin oleh seorang muslim, berdatanglah pedagang Arab untuk melakukan perdagangan, disamping melakukan perdagangan mereka juga melakukan dakwah. Dengan demikian proses penyebaran Islamisasi dapat berjalan dengan lancar melalui saluran perdagangan. Kemudian proses Islamisasi yang terjadi di Banjar juga melalui saluran pernikahan. Saluran Islamisasi melalui pernikahan berhasil membantu proses penyebaran Islam. Pernikahan dilakukan oleh para pedagang atau Ulama yang menikahi perempuan-perempuan dari etnis Banjar. Kemudian yang terakhir prose penyebaran Islam di Banjar melalui saluran kesenian. Saluran kesenian dikembangkan oleh Bubuhan Tutus, Bubuhan Tuan Guru, dan Bubuhan Jaba. Berbagai saluran kesenian Banjar, termasuk perubahan dalam seni lukis, senin pahat kaligrafi menunjukkan kentalnya pengaruh Islam (Saleh, 1980:140).

Kampung Banjarmasin pada awalnya tempat orang Melayu yang dipimpin oleh Patih Masih (sebagai kepala kampung), yang terletak antara pertemuan Sungai Barito dan Sungai Martapura, juga merupakan tempat pertukaran barang antara komunitas Melayu dengan Dayak Ngaju, dan menjadi tempat kegiatan perdagangan. Kemudahan transportasi antar daerah hulu sungai dan muara sungai berdampak pada berkumpulnya para pedagang dari berbagai daerah untuk melakukan transaksi perdagangan. Lama-kelamaan, sekitar pasar muncul bangunan-bangunan tempat penyimpanan barang-barang komoditas perdagangan dan rumah-rumah para pedagang mulai bermunculan, dan pada akhirnya di kampung Banjarmasin lahirlah masyarakat pedagang dan merupakan Kota Dagang (Ideham et al, 2003:47). Agama Islam menjadi agama resmi kerajaan dan penerapan hukum Islam di daerah Kesultanan Banjarmasin adalah sejalan dengan terbentuknya kesultanan dan dinobatkannya Sultan Suriansyah sebagai raja pertama yang beragama Islam.

Terbentuknya Kesultanan Banjarmasin menggantikan Kerajaan Negara Daha, yang beragama Hindu, telah mengubah menjadi kerajaan yang bercorak Islam. Islam terus berkembang di Banjarmasin. Gerak awal dari upaya Pangeran Suriansyah menyebarkan dan mengembangkan Islam secara luas kepada masyarakat ialah dengan mendirikan sebuah masjid. Namanya Masjid "Sultan Suriansyah", yang merupakan masjid pertama di kesultanan Banjarmasin pada abad ke-16 M. Masjid ini berdiri sebagai hasil musyawarah antara Sultan dan para pembesar kesultanan, dan masih ada hingga kini di Kampung Kuin, sudah beberapa kali dipugar (Basuni, 1986:35-36). Dalam hal ini, Sultan tidak bertindak atas kemauan sendiri, tetapi dibatasi oleh para petinggi kesultanan dan diatur dengan ketentuan kesultanan. Hal yang penting dalam menyebarkan Islam adalah peran dari para Sultan Banjarmasin, yang selalu menjadi tauladan bagi rakyatnya, yaitu antara lain dengan senantiasa memakai nama-nama Islam dan bertindak sesuai dengan cara-cara Islam. Tersebarnya agama Islam di daerah Banjarmasin ini juga tidak dengan paksaan maupun kekerasan. Ditunjang oleh ajaran Islam yang tidak membeda-bedakan golongan atau kasta, seperti yang ada pada agama Hindu.

Faktor lain ialah bahwa peng-Islam-an banyak ditunjang oleh peran dari golongan atas, yaitu pemegang tahta Kesultanan Banjarmasin beserta keluarganya. Hasil dari penyebaran 
Islam itu bukan saja tampak dalam bidang politik, sosial, dan keagamaan, tetapi juga dalam bidang budaya. Misalnya huruf Arab, yang digunakan dalam pelajaran membaca Al-Qur'an dan menghafal bacaan sholat, juga perjanjian yang dibuat antara Sultan Banjarmasin dengan VOC (Vereenigde Oost-Indische Compagnie atau Perusahaan Dagang Hindia Belanda) dan Inggris pada abad ke-17 M, ditulis dengan huruf Arab-Melayu. Demikian pula dengan historiografi tradisional berupa Hikayat Lembu Mangkurat, Hikayat Raja-raja Banjar dan Kotawaringin, dan Hikayat Banjar, semuanya ditulis dalam huruf Arab-Melayu. Menurut Zafry Zamzam, didalam bukunya Syekh Muhammad Arsyad al-Banjari, berpendapat bahwa sebagai Ulama Juru Dakwah ada dua orang Datu yang giat melakukan dakwah, yaitu Datu Kandang di bagian utara yang mengajar mengaji AlQur'an dan menghidupkan sembahyang Jum'at di masjid. Sedangkan Datu Sanggul berdakwah di bagian selatan. Beliau giat mengusahakan atau menghadiahkan tiangtiang kayu besi pada orang-orang yang akan mendirikan mesjid (Zamzam, n.y.:3).

Perkembangan Islam yang sangat berarti terjadi pada masa pemerintahan Sultan Tahmidullah II (Pangeran Nata Alam), sekitar tahun 1785-1808; dan Sultan Sulaiman (18081825), yang kedatangan seorang ulama besar yang bernama Syekh Muhammad Arsyad alBanjari, setelah kembali dari menuntut ilmu di dua kota suci di Mekkah dan Madinah. Dalam menyebarkan agama Islam, Syekh Muhammad Arsyad al-Banjari mendapat dukungan dengan disediakannya segala sarana dan fasilitas dalam menyebarkan agama Islam oleh Sultan.

\subsubsection{Ulama-Ulama Banjar Pada Abad XVI M Hingga XIX M dalam Islamisasi Kesulatanan Banjar}

Ulama atau tokoh agama terkemuka tentunya memiliki peranan penting dalam proses penyebaran agama Islam. Menurut Masfiah (Abdurrahman, 2009:4-5) dalam Sulaiman bahwa perkembangan pemikiran ulama Banjar mendapat pengaruh dari Aceh dan tahap-tahap pemikiran tersebut antara lain: (1) Perkembangan pemikiran dasar keagamaan yang mewarnai pemikiran keagamaan di dalam Kesultanan Banjar adalah yang berasal dari Jawa, yaitu Demak atau Giri yang hanya menyangkut tasawuf akhlak. Di sini tidak terlihat tandatanda bahwa ajaran kejawen turut masuk ke wilayah Kesultanan Banjar; (2) Paham mistik atau sufisme yang berasal dari Hamzah Fansuri sudah memasuki praktik keagamaan didalam Kesultanan Banjar beberapa saat setelah penduduk memeluk agama Islam dan telah ada yang berangkat ke Aceh dalam rangka menunaikan ibadah haji ke Mekkah. Paham ini tampaknya dominan sebagaimana terlihat pada Syekh Ahmad Syamsuddin al-Banjari yang ternyata sudah menggeluti persoalan tentang kejadian Nur Muhammad, salah satu prinsip dasar dari ajaran Tasawuf Wahdah Al-Wujud; dan (3) Sebagai reaksi yang muncul di Aceh yaitu berkembangnya faham sufisme dari Hamzah Fansuri, maka kelompok pemikiran Nuruddinal-Raniri yang menentangnya juga mendapat simpati dari rakyat Kesultanan Banjar.

Berikut adalah beberapa ulama yang memiliki pengaruh dan peranan besar dalam proses Islamisasi masa Kesultanan Banjar, antara lain:

\section{Syekh Arsyad al-Banjari}

Muhammad Arsyad Al-Banjari lahir di Lok Gabang wilayah Kecamatan Astambul, Kabupaten Banjar pada tanggal 15 Safar 1122 H. Muhammad Arsyad adalah anak yang cerdas. Dari beberapa sumber banyak dikatakan bahwa beliau sudah mampu membaca Al-Qur'an dengan baik ketika usianya 7 tahun. Karena kecerdasannya inilah, Sultan Tahlilullah yakni Sultan yang berkuasa pada masa itu tertarik dan menginginkan Muhammad Arsyad untuk 
belajar di istana. Awalnya keinginan tersebut ditolak oleh Ayahanda Muhammad Arsyad, namun karena keseriusan Sultan Tahlilullah membuat permintaan tersebut dikabulkan. Menginjak usia dewasa Muhammad Arsyad menempuh pendidikan di Makkah. Ia belajar dengan banyak tokoh yang juga memiliki pengaruh dalam penyebaran agama Islam di Nusantara seperti Abdul Samad Al-Palimbani, Abdul Wahab Al-Bigisi, dan Abdurrahman AlMisry. Muhammad Arsyad dan para sahabatnya ini seringkali disebut dengan 4 serangkai karena kebersamaan dan kekompakannya dalam menyelesaikan beberapa persoalan yang dihadapi masyarakat. Muhammad Arsyad menempuh pendidikan di Makkah selama 30 tahun dan di Madinah 5 tahun. Walau sudah menempuh pendidikan di Makkah dan Madinah, Muhammad Arsyad masih memiliki keinginan untuk melanjutkan pendidikan di Mesir. Namun keinginan tersebut tidak terlaksana karena di Madinah ia dan para sahabatnya bertemu dengan Ulama terkenal Mesir yakni Syekh Muhammad Ibn Sulaiman Al-Kurdi yang mengatakan bahwa Muhammad Arsyad dan para sahabatnya agar kembali untuk membina ajaran agama Islam ke kampung halaman Nusantara, karena dirasa sudah cukup memiliki ilmu yang mendalam. Atas nasehat tersebut akhirnya Muhammad Arsyad dan para sahabatnya memutuskan untuk pulang ke kampung halaman Nusantara, kecuali Abdul Samad AlPalimbani yang lebih memilih bermukim di Makkah. Tahun 1186 H Muhammad Arsyad sampai di Kesultanan Banjar Kalimantan. Langkah pertama yang beliau lakukan adalah dengan mendirikan lembaga pendidikan yang hampir sama seperti Pondok Pesantren. Tanah tempat pembangunan lembaga pesantren ini merupakan pemberian dari Sultan Tahmid Allah II yang sebelumnya Muhammad Arsyad meminta kepada Sultan Tahmid Allah II untuk diberikan sebidang tanah yang jauh dari pusat kerajaan. Alasanya karena tanah yang jauh dari pusat kerajaan adalah untuk mempermudah dalam membentuk pemukiman dan tata ruang penduduk baru. Tetapi tujuan utamanya adalah untuk mencetak kader-kader ulama, khususnya dari keluarga sendiri dan masyarakat pada umunya. Permintaan yang dilakukan Muhammad Arsyad mendapat dukungan penuh dari sultan saat itu, hal ini dibuktikan dengan dikerahkannya masyarakat untuk pembangunan masjid, asrama, perpustakaan, dan lahan pertanian.

Sementara pengajaran tentang agama Islam, Muhammad Arsyad memulainya dengan belajar Al-Qur'an, baca tulis Arab-Melayu, kemudian belajar bahasa Arab, serta belajar Nahwu dan Saraf yakni kitab-kitab yang dipelajari oleh para kader ulama di pesantren. Dalam pengajarannya para kader ulama ini dibimbing untuk beramal sholeh, beriman dan bertakwa, memiliki ilmu yang luas, serta memiliki pengabdian yang tulus. Bukan hanya itu Muhammad Arsyad juga melakukan pembaharuan dengan memperkenalkan gagasan-gagasan untuk mendirikan lembaga keagamaan dalam bentuk pendidikan Islam (Gafur, 2014). Dimana para calon ulama dan fuqaha' diberi pembelajaran untuk meningkatkan pemahaman mereka dalam praktek-praktek ajaran agama Islam dalam kehidupan. Selain itu Muhammad Arsyad juga mengusulkan pada Kesultanan Banjar untuk membentuk jabatan Mufti. Tujuannya adalah untuk menetapkan fatwa dari setiap persoalan yang muncul, mengayomi dan menggiring umat Islam agar mampu memahami dan mengamalkan ajaran Islam dalam kehidupan. Mufti pertama dalam Kesultanan Banjar adalah cucu Muhammad Arsyad yaitu Muhammad As'ad. Peran Muhammad Arsyad dalam proses Islamisasi pada Kesultanan Banjar cukup berpengaruh, dimana dalam pengajarannya Muhammad Arsyad juga menerapkan hukum Islam, seperti adanya hukum potong tangan bagi pencuri. Beliau juga telah banyak menulis buku, terutama yang menyangkut agama seperti fiqih, tasawuf, dan fiqih. Salah satu kitab karangannya adalah kitab Tufath Al-Raghibin Fi Bayan Haqiqat Iman Al- Mukminin Wama 
Yufsiduhu Min Riddah Al-Murtadin. Sebelum kehadiran para ulama, Islam di Kesultanan Banjar dalam prakteknya agama Islam masih belum berjalan maksimal karena tidak adanya bimbingan dan penjelasan mengenai ajaran agama Islam itu sendiri. Dalam pengajarannya menyebarkan agama Islam sejak kepulangannya dari Makkah, usia Muhammad Arsyad sudah 65 tahun paling tua diantara para sahabat lainnya. Muhammad Arsyad meninggal diusianya yang ke 105 tahun yakni pada tahun $1227 \mathrm{H}$.

\section{Syekh Muhammad Nafis bin Idris al-Banjari}

Sebagai bagian dari dunia Islam dan sekaligus dunia Melayu, kawasan Kalimantan Selatan juga tidak lepas dari pengaruh ajaran tasawuf. Salah seorang ulama tokoh tasawuf yang terkenal di Kalimantan Selatan khususnya di Banjar yang pernah mengembangkan ajaran tasawuf serta menulis beberapa kitab yang berisi ajaran tasawuf ialah Syekh Muhammad Nafis al-Banjari (Baihaqi, 2019). Syekh Muhammad Nafis bin Idris bin Husin, demikian nama lengkapnya. Tanggal kelahirannya sampai sekarang belum diketahui secara pasti, namun diperkirakan sekitar tahun 1148 H (1735 M). dilahirkan di salah satu Desa Martapura Kabupaten Banjar, Provinsi Kalimantan Selatan . Berasal dari kalangan keluarga bangsawan atau kesultanan Banjar yang bersambung hingga Sultan Suriansyah (1527-1548 M) (Abdurrahman, 2009).

Pendidikan awal Syekh Muhammad Nafis tidak begitu jelas, tetapi kemungkinan besar bermula dari menuntut agama di Kalimantan. Kecenderungan Syekh Muhammad Nafis terhadap tasawuf mulai terlihat sejak kecil. Syekh Muhammad Nafis melanjutkan pendidikannya di Haramayn, Makkah dan Madinah (Rodiah, 2015). Saat Syekh Muhammad Nafis berada di Makkah pada tahun $1200 \mathrm{H}$, atas permintaan beberapa sahabatnya beliau menulis kitab yang diberi judul ad-Dur al-Nafis. Kitab tersebut ditulis dengan bahasa Melayu huruf Arab, dengan maksud agar dapat dimanfaatkan oleh mereka yang belum mengerti bahasa Arab dengan baik (Baihaqi, 2019). Selain itu karya Syekh Muhammad Nafis adalah Majmu' al-Asrar (perhimpunan segala rahasia), Kanzus Sa'adah (perbendaharaan kebahagian) dan beberapa karya lain yang masih belum diketahui pasti kesahihan karangan beliau, namun kitab ad-Durr al-Nafis yang merupakan karya paling berpengaruh dibanding dengan karyanya yang lain (Akhir, 2011).

Nama kitab ad-Durr an-Nafis selengkapnya adalah ad-Durr an-Nafis fi Bayan Wahdah al-Af'al wa al-Asma' wa ash-Shifat Zat at-Taqdis (Mutiara yang Indah Pada Menyatakan Wahdat Af'al dan Asma dan Shifat dan Zat yang Suci). Kitab ini selesai ditulis setelah waktu isya' pada malam Rabu, 27 Muharam $1200 \mathrm{H}$ atau 30 November 1785 M. Didalamnya menjelaskan tentang ajaran tauhid tasawuf tingkat tinggi tentang keesaan Allah dari zat, shifat, asma', dan af'al (Rodiah, 2015). Dalam masalah ilmu tauhid Syekh Muhammad Nafis menganut paham Asy'ari atau disebut aliran Ahlusunnah Wal Jama'ah, sedangkan dalam bidang ilmu tasawuf Syekh Muhammad Nafis mengikuti paham Syekh al-Junaydi al-Baghdadi (Sahabat, 2010).

Syekh Muhammad Nafis menganut berbagai tarekat, yaitu Tarekat Qadariyah, Tarekat Satariyah, Tarekat Naqsabandiyah, Tarekat Khalwatiyah, Dan Tarekat Sammaniyah (Baihaqi, 2019). Dalam mengungkapkan tarekat, Syekh Muhammad Nafis menggunakan simbol, yaitu tariqah (jalan), pakaian, makanan, dan minuman. Mungkin fungsi tarekat itu bagi beliau bagaikan jalan, pakaian, makanan, dan minuman bagi jasmani, atau bermakna semua tarekat itu diamalkannya bagaikan beliau selalu harus berjalan, berpakaian, makan, dan minum setiap hari, yang itu semua merupakan keperluan mendasar dalam kehidupan (Isa, 2001). 
Dalam kitabnya al-Durr al-Nafis diketahui guru-guru dari Syekh Muhammad Nafis adalah Abd Allah Hijazi as-Sharqawi al-Misriyy, Mawlana Syeikh Siddiq ibn Umar Khan, Mawlana Syeikh 'Abd al-Rahman Ibn 'Abd al-'Aziz al-Maghribi al-'Amri R.A, Saiyyidi Mustafa ibn Kamal al-Din al Bakri, Mawlana Syeikh Muhammad ibn 'Abd al-Karim al-Samman, dan ramai lagi (Akhir, 2011). Tidak ada informasi atau catatan tentang apakah Syekh Muhammad Nafis di Makkah dan Madinah belajar bersama dengan Syekh Abdul Shamad al-Falimbani, Syekh Muhammad Arsyad al-Banjari, dan rekan-rekan mereka lainnya. Tetapi besar kemungkinan masa belajar Syekh Muhammad Nafis al-Banjari di Makkah bersama dengan Syekh Abdul Shamad al-Falimabni dan Syekh Muhammad Arsyad al-Banjari dengan melihat daftar nama-nama guru Syekh Muhammad Nafis al-Banjari (Baihaqi, 2019).

\section{Syekh Abdul Hamid Abulung}

Syekh Abdul Hamid Abulung (Datu Abulung) merupakan salah satu ulama sufi di Kalimanatan Selatan. Menurut Amin (2008:267) dalam Aizid (2016:225) bahwa Datu Abulung hidup pada masa kepemimpinan Sultan Tamhidullah yang berkuasa di kesultanan Banjar pada tahun 1778-1808 M. Dalam penyebaran agama Islam di daerahnya, Datu Abulung termasuk dalam generasi pertama yaitu fase pembentukan jaringan, didasarkan atas generasi yang belajar di Timur Tengah oleh Arsyad al-Banjari sebagai pelopornya karena hidup pada masa yang sama (Hanafi, 2017).

Berdasarkan pemaparan Syafruddin dalam Kolis (2012) gelar datu yang diberikan kepada Syekh Abdul Hamid Abulung menandakan bahwa beliau merupakan tokoh yang disegani sebab mempunyai kemampuan supranatural dan keistimewaan lain yang sebanding dengan pengetua adat. Adapun gelar syekh yang diberikan kepada beliau menunjukkan bahwa Abdul Hamid adalah tokoh agama yang memiliki ilmu tinggi, murid yang banyak, dan setidaknya dalam tradisi tasawuf mempunyai kedudukan sebagai khalifah, murshid, maupun badal.

Dalam lingkungan Kesultanan Banjar, tasawuf sebagai salah satu sarana penyebaran agama Islam di Banjar terdiri atas dua jenis. Pertama tasawuf falsafi yang dibawa oleh Datu Abulung dan Syek Muhammad Nafis al-Banjari dan kedua tasawuf akhlaki dibawa oleh Syekh Asryad al-Banjari. Beberapa ulama Banjar lainnya mengeluarkan karya diantaranya karya dari Syekh Muhammad Arsyad al-Banjari yaitu kitab Sabil al-Muhtadin dan karya dari Syekh Muhammad Nafis al-Banjari berupa kitab Durunnafis. Sedangkan Datu Abulung tidak banyak mengeluarkan karya (Hidayat, 2018).

Adapun isi pengajaran yang disampaikan oleh Datu Abulung dilandaskan pada paham wujuddiyah, didasarkan kepada pemikiran Ibn 'Arabby (1165-1240 M). Menurut Syukur dalam Kolis (2012) pola pemikiran tasawuf yang dianutnya sebagian besar menyatakan bahwa didapatkan dari pengaruh aliran Ittihad Abu Yazid al-Bustami, paham hulul-nya al-Hallaj, pemikiran Hamzah Fansuri, Syamsudin Sumatrani, dan Syekh Siti Jenar dari Jawa. Kondisi sosial pada masa Kesultanan Banjar yang pada saat itu terbuka kepada siapapun termasuk dalam hal penyebaran aliran pemahaman agama maka membuat Datu Abulung dalam mengajarkan pemahamannya (tasawuf) memiliki akses yang mudah dan dapat mengembangkannya. Namun dalam melakukan penyebaran pemaham tasawufnya, Datu Abulung mendapat kecaman dari Sultan Tahmidullah II karena ajarannya yang dianggap kontroversial dan sebagai akibatnya beliau dihukum mati. 


\section{Simpulan}

Berdasarkan pemaparan yang telah dijelaskan, dapat diambil kesimpulan bahwa proses Islamisasi pada Kesultanan Banjar banyak di Pengaruhi oleh Kesultanan Demak karena bantuannya dalam perang melawan Keraajaan Daha. Atas kemenangannya itulah Kesultanan Banjar kemudian memeluk agama Islam karena adanya kesepakatan dengan Kesultanan Demak. Faktor lain proses Islamisasi pada Kesultanan Banjar adalah adanya dukungan dari para petinggi di Kesultanan Banjar dan juga masuknya para pedagang muslim disertai dengan dakwah yakni melalui berdagang, pernikahan, dan pendidikan. Awal mula Islam di Kesultanan Banjar hanya terdiri dari golongan kaum minoritas yakni di peluk dari kalangan etnis Melayu, sedangkan dari etnis Dayak sendiri berjalan lamban. Penerapan Islam pertama di Kesultanan Banjar terbatas pada pengucapan kalimat Syahadah saja, dan belum ditindaklanjuti pada penerapan atau pengalaman ajaran agama islam dalam kehidupan sehari. Namun sejak kedatangan para ulama Islam, perkembangan Islam mengalami banyak perubahan. Ulamaulama Islam yang telah banyak memberikan pengaruhnya terhadap Islamisasi di Kesultanan Banjar Kalimantan adalah Syekh Arsyad al-Banjari, Syekh Muhammad Nafis bin Idris alBanjari, dan Syekh Abdul Hamid Abulung dan membuat sebagian besar masyarakat Kalimantan memeluk agama Islam.

\section{Daftar Rujukan}

Abdurrahman. n.d. (2009). Mengenal Syekh Muhammad Nafis al-Banjari, Kitab al-Dur al-Nafis dan Ajaran Tasawufnya. Kelompok Studi Islam Banjarmasin.

Aizid, R. (2016). Sejarah Islam Nusantara. Yogyakarta: DIVA Press.

Akhir, N. S. (2011). Pengaruh Syeikh Muhammad Nafis al-Banjari di Kalimantan Selatan Berhubung Ilmu Tasawuf. Prosiding Nadwah Ulama Nusantara (NUN) IV, Universiti Malaya.

Baihaqi, A. (2019). Takhrij al-Hadisy Kitab al-Dur al-Nafis Karya Syekh Muhammad Nafis al-Banjari. Fakultas Ushuluddin Universitas Negeri Syarif Hidayatullah. Skripsi.

Basuni, Ahmad. (1986). Nur Islam di Kalimantan Selatan. Surabaya: Bina Ilmu.

Gafur, A. (2014). Islam Di Kesultanan Banjar Pada Abad Ke 19 M Dan Peran Muhammad Arsyad Al-Banjari. (Online),(https://www.google.com/search?Client=firefox-b-d\&q=islam+di+kesultanan+banjar+ pada+abad+ke+19+M+dan+peran+Muhammad+arsyad+al+banjari\#) diakses pada 1 September 2019.

Hanafi, H. (2017). Geanologi Kajian Hadis Ulama al-Banjari. Journal of Islamic Studies and Humanities. 2(2), 172-174. Dari http://millati.iainsalatiga.ac.id/index.php/millati/article/view/1255.

Hardiati, Sri. E. (2008). Sejarah Nasional Indoneseia Jilid III, Zaman Pertumbuhan dan Perkembangan Kerajaan Islam di Indonesia. Jakarta: Balai Pustaka.

Hidayat, R.A. (2018). Sinkretisme dalam Naskah Sastra Mistik. Jurnal SMaRT Studi Masyarakat, Religi, dan Tradisi, 4(1), 81-82. Dari https://blasemarang. kemenag.go.id/journal/index.php/smart/article/ download $/ 585 / 321$.

Ideham, M. Suriansyah et al. (2003). Sejarah Banjar. Banjarmasin: Balitbangda (Badan Penelitian dan Pengembangan Daerah) Provinsi Kalimantan Selatan.

Isa, A. (2001). Ajaran Tasawuf Syekh Muhammad Nafis al-Banjari. Jakarta: PT Raja Grafindo Persada.

Kartodirdjo, S. (1987). Pengantar Sejarah Indonesia Baru: 1500-1900, Dari Emporium Sampai Imperium Jilid I. Jakarta: PT Gramedia.

Kolis, N. (2012). Nur Muhammad dalam Pemikiran Sufistik Datu Abulung di Kalimantan Selatan. Jurnal Ilmiah Ilmu-Ilmu Keislaman, 11(2), 177-178. Dari https://jurnal.uin-antasari.ac.id/index.php/albanjari/article/view/425/326.

Lapian, A. B. (2008). Pelayaran dan Perniagaan Nusantara Abad ke-16 dan 17. Jakarta: Komunitas Bambu.

Rodiah. (2015). Insan Kamil Dalam Pemikiran Muhammad Nafis Al-Banjari Dan Abdush-Shamad Al-Falimbani Dalam Kitab Ad-Durr An-Nafis Dan Siyar As-Salikin (Sebuah Studi Perbandingan). Studi Insania Vol. 3, No. 2 IAIN Antasari Banjarmasin. 
Jurnal Integrasi dan Harmoni Inovatif Ilmu-Ilmu Sosial (JIHI3S), 1(2), 2021, 227-237

Saleh, I. (1983). Sekilas Mengenai Daerah Banjar Dan Kebudayaan Sungainya Sampai Dengan Akhir. Kalimantan Selatan: Departemen Pendidikan dan Kebudayaan.

Saleh, M. I. (1980). Sedjarah Bandjarmasin. Bandung: Balai Pendidikan Guru.

Sulaiman. (2014). Ajaran Tasawuf dalam Naskah Sirr Al-Lathif, (Online), (https://www.academia.edu/31256970/Ajaran_Tasawuf_dalam_Naskah_Sirr_Al-Lath\%C4\%ABf AJARAN TASAWUF DALAM NASKAH SIRR AL-LATH\% C4\%AAF The sufi sm teaching in the Sirr Al-Lath\%C4\%ABf SULAIMAN), diakses 29 September 2019.

Tim Sahabat. (2010). Manakib Syekh Muhammad Nafis al-Banjari dan Ajarannya. Kalimantan Selatan: SAHABAT.

Yatim, B. (1997). Sejarah Peradaban Islam. Jakarta: Rajawali Press.

Zamzam, Zafry. (n.y.). Syekh Muhammad Arsyad alBanjari sebagai Ulama Juru Dakwah. Banjarmasin: IAIN [Institut Agama Islam Negeri] Antasari.

Zuhri, S. (1979). Sejarah Kebangkitan Islam dan Perkembangannya di Indonesia. Bandung: Al-Ma'arif. 